\title{
Health and nutrition education unit in a children's hospital
}

\author{
BERNARD M LAURANCE, BRENDA LAWRIE
}

British Medical fournal, 1978, 2, 1469-1471

"Prevention is better than cure" is probably more applicable to promoting health in childhood than in any other age group.

Nutrition rehabilitation units ${ }^{1}$ have been established in several developing countries in an effort to prevent the protein energy malnutrition that is so common in most of them. A similar sort of unit, modified to include all aspects of child care, seemed to be needed in the underprivileged community of the east end of London, where about $35 \%$ of the children are the sons and daughters of immigrants; where social classes IV and V predominate; and where there are many single-parent families and families with one parent in prison.

The health and nutrition education unit, so far as we know the first in Great Britain, was established in the Queen Elizabeth Hospital for Children in September 1976, and we describe here the work of its first 18 months.

\section{The unit and the population it serves}

The unit was initially established in a screened-off area of the hospital's outpatient waiting hall. Later it moved to an office, which provided more privacy.

The Queen Elizabeth Hospital for Children is the only children's hospital in the east end of London, although there are paediatric departments at the two teaching hospitals (St Bartholomew's and the London) with which the Queen Elizabeth hospital is associated. Because few general practitioners live in the area the hospital (148 beds) provides primary care for about 6000 new patients a year who attend the casualty department. There are about 4700 new referrals

Queen Elizabeth Hospital for Children, London E2 8PS BERNARD M LAURANCE, MB, FRCP, consultant paediatrician BRENDA LAWRIE, RSCN, HVDIP, sister in charge

to the outpatient clinics, the hospital also serving as a regional referra centre.

In the area served by the hospital most of the local authority housing consists of prewar flats and high-rise blocks. Among privately owned accommodation, multioccupied houses are common and tenement blocks remain in some localities. Elsewhere prefabricated dwellings are still used and open ground is used by caravan dwellers and gypsies. In the last census in $1971,11 \%$ of the accommodation had either an outside toilet or a single cold water tap or both. As well as the large industries that employ some of the inhabitants, there are many small industries (clothing factories, light engineering, and furniture making) and markets (Smithfield, Billingsgate, Petticoat Lane, Spitalfields), while $15 \%$ of the working population are unemployed.

\section{The unit's aims}

We considered that many of the parents bringing their children to hospital might benefit from advice about the best ways of feeding them and keeping them healthy and learning simple home economics. Their children's "illnesses," though often real enough, are sometimes the result of mismanagement or an adverse environment. Most have already had some health education in the community, but the hospital also sees families who are poor clinic attenders and who do not use primary health care services.

From the outset we made it clear to the area and district community physicians in child health, general practitioners, health visitors, midwives, health education officers, social workers, and others that the unit aimed to augment their work rather than replace it.

\section{Staffing, administration, and source of referrals}

The unit is run by a former ward sister (BL) of the hospital, who was previously a district nurse and a health visitor and who has the added advantage of having lived locally as a child and therefore of knowing the area. Her post was created from the existing funded establishment of the hospital, extra salary costs thus being avoided. She is responsible to the senior nursing officer of the hospital and liaises at short weekly meetings with one of the consultant medical 
staff (BML), but informality has been the aim from the outset and all grades of medical, nursing, and social services staff work directly with her. Referrals are made from all departments of the hospital by all grades of medical and nursing staff and increasingly from community health staff, particularly health visitors and general practitioners. She also gives advice to the parents of children waiting to be seen in the various clinics.

\section{The work of the unit}

During the first 18 months the scope of the unit's work widened. The main areas of health education included accident prevention in play areas, on the roads, and at home (scalds, burns, falls, poisoning); correct nutrition-immigrant diets, special diets, vitamins, and baby feeding (breast- and bottle-feeding and weaning); dental health; immunisation; and play facilities.

Type of referrals. (Total number of interviews 608)

\begin{tabular}{|c|c|}
\hline & No $(\%)$ of referrals \\
\hline $\begin{array}{lll}\begin{array}{l}\text { Feeding difficulties or nutrition problems } \\
\text { General child care problems }\end{array} & \ldots & \ldots \\
\text { Accidents (home and outside) and poisons } & \ldots & \ldots \\
\text { Advice to mothers about home care of a sick child } & \ldots \\
\text { Specific care problems of handicapped children } & \ldots \\
\text { Chasing failed follow-up attenders when children had } \\
\text { worrying illnesses } \\
\begin{array}{llll}\text {.. } & \ldots & \ldots\end{array}\end{array}$ & $\begin{array}{r}158(41) \\
73(19) \\
43(11) \\
73(19) \\
19(5) \\
19(5)\end{array}$ \\
\hline Total (Sept 1976 to Feb 1977) & 385 \\
\hline
\end{tabular}

The table shows that about $40 \%$ of the referrals were for feeding problems, which included such difficulties as food refusal, posseting, aerophagy, inadequate nutrition, and obesity, as well as requests for advice about breast-feeding, artificial feeding, and the introduction of solids. Often these apparently superficial difficulties disclosed more severe problems. The Bengali patients were referred to the nearby Spitalfield's project, where Asian families are advised how to budget within their income; how to use butter and margarine to make ghee; and how to substitute locally available foods and vegetables for the more expensive imported goods.

The 73 general child care problems included all those familiar to general practitioners, health visitors, and paediatricians. Accident cases seen in the casualty department and other departments were notified to the unit, especially if it seemed likely that accidents would recur, either to the same child or to another in the family. Avoiding accidental poisoning was an obvious example, but, perhaps even more satisfying, landlords were persuaded to fence off a balcony from which a child had fallen and a play area in a block of flats from which children had strayed on to the road. The unit was not routinely concerned in cases of non-accidental injury, which were usually managed separately.

In 73 of the cases dealt with by the unit the sister was able to co-ordinate the services of the general practitioner, district nurse, and health visitor so that children could be cared for at home rather than being admitted to hospital. This happened only when home and social circumstances allowed it, and all too often the homes were unsuitable and the mothers incapable. The lack of "extended family" help is nowhere better illustrated than in the community that surrounds the hospital.

Home visits were made to complement the work of the health visitor to families whose low standards of care were causing concern or to provide continuing supervision for patients who presented paediatric nursing problems. Though health visitors managed most problems very adequately they were often grateful for the unit sister's knowledge of a child's problems in hospital or of specialised techniques such as gastrostomy feeding, which helped to ease the transition of care from hospital to home.

Telephone consultation-Once the unit had been established health visitors, social workers, and others increasingly sought advice over the telephone about nursing care and behavioural and other problems. Advice about where and to whom to refer patients with particular problems proved to be a mutually useful service.

Meetings-Personal contact both inside and outside the hospital was valuable in stimulating communication. The unit sister talked to local health visitors, parent groups, doctors, hospital and community nurses, and older schoolchildren about all aspects of health education. Discussion of the dietary problems specific to immigrants, using relevant publications, ${ }^{2}$ proved particularly valuable.
District health education departments-Liaison with these departments ensured that advice about such topics as feeding, accident prevention, immunisation, dental care, etc was co-ordinated. All too often advice used to be conflicting, but such co-ordination has reduced this considerably.

Displays-Waiting areas in the outpatient and casualty departments were used to display a wide variety of health education posters about immunisation, dental health, accident and poisoning prevention, and good feeding practices. Posters and pamphlets on these topics (if possible in the various Asian languages), which were available from racks in the two waiting areas, were supplied by the district health education officers and other sources (the Health Education Council, Community Relations Commission, General Practitioner Film Services Ltd, and the Royal Society for the Prevention of Accidents). The home accident prevention display (see figure) showed safety

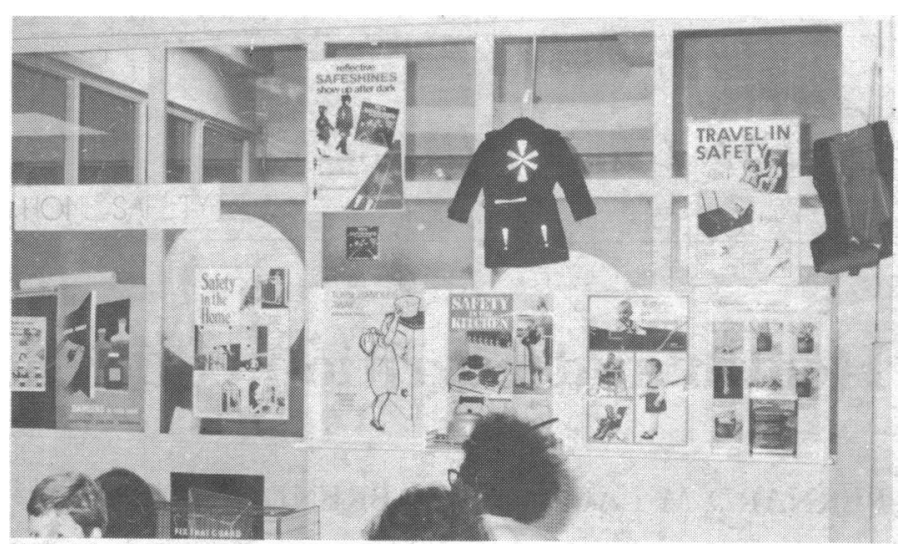

Accident prevention display in the outpatient waiting area.

equipment for the home such as a medicine safety cabinet, fireguards, guards to protect saucepans from being pulled off stoves, luminous strips to stick on clothes for better visibility during darkness, bottle sterilising equipment, and a child's car safety seat. Visiting parents took a great interest in these displays, though interest sometimes led to removal-a hazard of the crime-riddled area around the hospital. More recently, a film slide projector was installed to show health education material on a daylight screen in a partitioned-off area of the outpatient waiting hall.

\section{Discussion}

From the outset we have kept records of as many activities as possible in the knowledge that the work must be evaluated if continuation, let alone extension, is to be justified, but it is difficult to produce a statistical analysis that measures the improvement in health of the population served by the unit. Nevertheless, the warmth of welcome for the unit's work from the community physicians in child health, health visitors, midwives, district nurses, social workers, and general practitioners has convinced us that our unit is a useful adjunct to the work of child health clinics and district health education departments. Since the unit opened health visitors from the three local districts have visited the hospital more regularly, thereby co-ordinating care more helpfully.

Although the unit costs little to run, it was several years before a salary for the sister could be found; and the work of the unit has grown to such an extent that an additional appointment is already needed. We hope that a health visitor will work with us in the hospital as a member of the unit so that we can maintain even closer relationships with community health staff. The administrative problems of employing a health visitor in a hospital need to be overcome. For example, no car allowance for home visiting is currently available, though mileage allowance is payable.

Originally we had intended that the sister should give talks and practical demonstrations of feed preparation in the out- 
patient waiting hall. In practice this has not been possible, principally because of the continuous movement of the parents as they are called to see the doctor. Unlike parents in developing countries, the mothers attending our hospital will not wait once they have seen the doctor, and the one-to-one interview has therefore proved more valuable. This means that a unit need not necessarily be sited in the outpatient or casualty department but could be in any convenient room of a hospital, though it is desirable to be near to the waiting areas. An outside telephone is essential.

We feared resentment from community medical, nursing, and social work colleagues lest they saw the establishment of the unit as a sort of takeover bid, but the reverse has been the case. We explained our aims carefully before we began, and the warm reception encouraged us not only to continue but to write this account in the belief that others may wish to adapt these ideas to their particular area. The scope for community and hospital research is considerably broadened and we hope to develop this further. The unit has already helped in evaluating oral electrolyte solutions for the outpatient treatment of gastroenteritis. ${ }^{3}$

The work of the unit grows and must expand. For example, all types of accidents constituted only $11 \%$ of the unit's referrals during its first 18 months, but there were probably many more accident cases that were not referred. In Great Britain 200000 children under 5 years and another 144000 aged 5 to 14 have accidents in the home each year. ${ }^{4}$ We recognise that we are not coping with this problem and are looking for ways of doing so.

This project could not have started without the encouragement and help of Miss B M Barchard, chief nursing officer of the Hospitals for Sick Children, and Miss B S Beech, senior nursing officer of the Queen Elizabeth Hospital for Children, whom we thank most warmly. Many others have co-operated and advised, especially Dr J Richards, Dr L Fry, Dr A Brown, Dr J Davies, Miss S Mowat, Miss S Preston,

Miss V Packer, Mr G Peters, and Miss I Tauber.

We also gratefully acknowledge gifts towards the projector from Messrs Cow and Gate and J Wyeth and of accident prevention equipment from Mothercare Ltd.

Miss O'Neill kindly typed the manuscript.

\section{References}

1 Schneiderman, I, Bennett, F J, and Rutishauser, I H E, fournal of Tropical Pediatric and Environmental Child Health, 1971, 17, 25.

2 Jivani, S K M, Archives of Disease in Childhood, 1978, 53, 69.

3 Hutchins, P, et al, Lancet, 1978, 1, 1211.

${ }^{4}$ British Medical fournal, 1978, 1, 1561.

(Accepted 14 September 1978)

\title{
A Modern Epidemic
}

\section{Road accidents and the unfit driver}

\author{
BY A SPECIAL CORRESPONDENT
}

British Medical fournal, 1978, 2, 1471-1473

\section{Illness and disability}

In 1957 a London bus driver fainted at the wheel and killed nine people at a bus stop, and in $1963^{1}$ a driver known to have coronary artery disease drove his bus into a river in New York City, drowning six passengers. Such events are, however, exceedingly rare. In 24 years (406000 man years) only 127 London Transport drivers became acutely ill at the wheel, causing 59 accidents. $^{2}$ London Transport, of course, has a rigorous surveillance system; even so, few conditions were picked up at medical examinations that would have made private motoring unsafe. And even private drivers have a good record.

Sudden illness is a cause of 1-2 per 1000 accidents in most detailed studies. ${ }^{3}{ }^{4}$ Chronic conditions contributed to perhaps 5 per 1000 serious accidents in one survey, ${ }^{3}$ but there is evidence that such people may more than compensate for disabilities by taking extra care and even have a better accident record than healthy drivers. ${ }^{4}$

Thus illness appears to contribute little to road accidents. Even with heart disease (the commonest cause of collapse at the wheel) the driver usually has time to stop and usually injures no one else. ${ }^{5}$ On the other hand acute illness is a difficult cause to assess in accident studies as it may be masked by severe injury; an American study of drivers dying within 15 minutes of a single-vehicle accident showed that $15 \%$ had coronary heart disease or other serious illness. ${ }^{1}$ But as sudden illness is often quite unforeseen such accidents could not always be prevented. Epilepsy, however, clearly one of the conditions most hazardous for driving and the only absolute "bar" disability for driving heavy goods and public service vehicles, is sometimes concealed from licensing authorities, especially by professional drivers. ${ }^{5}$

\section{DECLARING DISABILITY}

The GP or consultant has a particular responsibility for urging patients to declare disabilities, especially now we have licences valid to the age of 70 and three-yearly declarations of health for driving licence renewal have ceased; for the driver now has a statutory duty to notify the Driver and Vehicle Licensing Centre of any relevant and prospective disabilities. (These are fully discussed in Medical Aspects of Fitness to Drive..$^{5}$ ) A doctor who has failed to tell a patient not to drive could be held negligent in law if there is an accident. Prospective disabilities (which may become relevant disabilities that preclude driving) are difficult for the doctor, and if he does not wish the patient to know that he is likely to develop a disability or get worse he must watch carefully for the time when driving should stop. Is it, however, expecting too much of human nature to leave the initiative entirely with the driver to notify the Licensing Centre-especially when he may depend on his car? 